\title{
MORPHOLOGY AND VARIATIONS OF BRACHIAL ARTERY IN
} CADAVERS

\section{Jessy Rose George ${ }^{* 1}$, Joseph Francis², Jeffy Elizabeth Samuel ${ }^{2}$, Thomas Francis².}

${ }^{*}$ Associate Professor, Department of Anatomy, Government Medical College, Kozhikode, Kerala, India.

${ }^{2}$ Department of Anatomy, Government Medical College, Kozhikode, Kerala, India.

\section{ABSTRACT}

Background: The study of brachial artery is an important arterial conduit from the clinical point of view to anatomists, general surgeons, radiologists, plastic surgeons, and even cardiovascular thoracic surgeons in the conduct of reparative surgery.Therefore, the present study was designed to study the course, branching pattern and termination of Brachial Artery and its clinical significance of these variations.

Materials and Methods: The present study was conducted on 30 upperlimbs of 15 cadavers embalmed \& belonging to theDepartment of Anatomy, Govt. Medical College,Alappuzha over the period of 1 year. By conventional dissectionmethod a longitudinalincision was given along the midline of arm through the deep fascia, inferiorup to cubital fossa. Brachial artery was identified, cleaned \& dissected and assessed the length of brachial artery, level of termination of brachial artery, variation in the branching pattern and the course in relation to the median nerve was noted.

Results: The average length of the brachial artery was $25.23 \mathrm{cms} .73 .3 \%$ of the brachial artery followed the classical pattern as given in Gray's Anatomy. Variation in the branching pattern, presence of accessory brachial artery, origin of profunda brachial artery was noted. 3.3\% trifurcation of brachial artery into Radial, Ulnar \& Common interosseous at the level of neck of radius.Brachial artery terminated at the level of neck of radius in $76.67 \%$, radial tuberosity $13.33 \%$, mid arm3.33\%, proximal arm $6.67 \%$.

Discussion and Conclusion: Variationsof brachial artery in its relationship with the median nerve, pattern and level of termination are common. These may complicate arm surgical exposure, flap and vascular surgery. Hence, Knowledge of possible variations in the branching pattern of various arteries is important during vascular and reconstructive surgery.

KEY WORDS: Brachial artery; Radial artery; Ulnar artery; interosseous artery; Accessory arteries.

Address for Correspondence: Dr. Jessy Rose George, Associate Professor, Department of Anatomy, Government Medical College, Kozhikode, Kerala, India.E-Mail: jessyrose@gmail.com

Access this Article online

Quick Response code

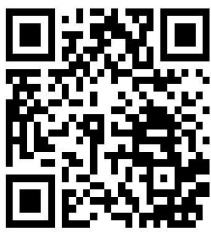

DOI: $10.16965 /$ ijar.2019.202

Journal Information

International Journal of Anatomy and Research

ICV for 2016 ISSN (E) 2321-4287 | ISSN (P) 2321-8967

90.30 https://www.ijmhr.org/ijar.htm DOI-Prefix: https://dx.doi.org/10.16965/ijar

\section{Article Information}

Received: 16 Apr 2019

Peer Review: 16 Apr 2019

Revised: None
Accepted: 20 May 2019

Published (O): 05 Jun 2019

Published (P): 05 Jun 2019

\section{INTRODUCTION}

Brachial artery (BA) is the main artery of the arm. It begins at the lower border of teres major muscle as a continuation of the Axillary artery and terminates by dividing into radial artery (RA) and ulnar artery (UA) at the level of the neck of radius in cubital fossa [1]. The BA is wholly superficial, covered anteriorly only by skin, superficial and deep fasciae. The bicipital aponeurosis crosses it anteriorly at the elbow, separating it from the median cubital vein at its lower part. The median nerve (MN) crosses it from lateral to medial side near the distal attachment of coracobrachialis. BA is posteriorly 
related to the long head of triceps, separated by the radial nerve and profunda BA (PBA), and then successively by the medial head of triceps, the attachment of coracobrachialis and brachialis [2]. Proximally, the MN and coracobrachialis lie laterally while distally the biceps muscle overlap the artery. Proximally, the medial cutaneous nerve of the forearm and ulnar nerve lie medially, while distally the MN and basilic vein lie medially $[3,4]$. Two venae committantesrunning with the BA, connected by transverse and oblique branches. Branches of BA are Profunda Brachial Artery, superior ulnar collateral artery (SUCA), middle and inferior ulnar collateral artery, muscular branches, nutrient branch, and two terminal branches are Radial Artery and UInar Artery.

Hence, the study of brachial artery is an important arterial conduit from the clinical point of view to anatomists, general surgeons, radiologists, plastic surgeons, and even cardiovascular thoracic surgeons in the conduct of reparative surgery $[5,6]$. Therefore, the present study was designed to study the course, branching pattern and termination of Brachial Artery and its clinical significance of these variations.

\section{MATERIALS AND METHODS}

The present study was conducted on 30 upper limbs of 15 cadavers (26 Males \& 4 Females) embalmed $\&$ belonging to the Department of Anatomy, Govt. Medical College, Alappuzha over the period of 1 year. These were labelled from 1-30. Rt or Lt corresponding to right or left limbs respectively. By conventional dissection method a longitudinal incision was given along the midline of arm through the deep fascia, inferiorlyup to cubital fossa. Brachial artery was identified, cleaned \& dissected to its origin, proximally the continuity with Axillary artery at the level of lower border of teres major.

Distally in the cubital fossa the bicipital aponeurosis was divided and the brachial artery was traced up to its bifurcation. The branches were identified and if variations seen, it was studied with meticulous dissection and observation. The course in relation to the median nerve in the arm was noted. Venae committantes were identified and removed. For the morphological study the parameters used were
Length of brachial artery, level of termination of brachial artery, variationin the branching pattern and the course in relation to the median nerve was noted. Normal and abnormal terminations of the brachial artery were recorded and photographed.

\section{RESULTS}

In the present studythe average length of the brachial artery was $25.23 \mathrm{cms}$ (ranging from $18 \mathrm{~cm}$ to $26 \mathrm{cms}$ ). So, regarding the length of the artery, my study coincides with Patnaik et al.In the present study, out of 30 specimens studied 73.3\% of the brachial artery followed the classical pattern as given in Gray's Anatomy.Variations recorded in 8 cases.

In all 30 specimens, the brachial artery was in continuation with axillary artery at the lower border of teres major muscle. The brachial artery in middle third part gives a branch, Accessory brachial artery (Fig :1a) in one case (3.3\%) among the 30 limbs that passes lateral to the main trunk, later coursed deep to the median nerve to join with the main trunk about $12 \mathrm{~cm}$ distally. In $6.67 \%$ of cases, superficial brachial artery encountered crossed superficial to median nerve in two cases (Fig:1b). Variation in the branching pattern included Superficial brachioradial Artery was present in $6.67 \%$ cases, Accessory brachial artery was present in $3.33 \%$ case respectively. Origin of profunda brachial Artery as a common trunk along with SUC artery $3.3 \%$ case. Dilated tortuous brachial Artery was found anterior to the median nerve in the entire arm in $3.3 \%$ case.

Trifurcation of brachial artery seen in 1 case (3.3\%) into Radial Artery, Ulnar Artery, Common interosseous Artery (Fig :2a). In $6.67 \%$ of cases median nerve related posterior to brachial $A$ in the entire arm. In one case (3.3\%) trifurcation of brachial artery into Radial, Ulnar and common interosseous at the level of neck of radius was recorded.

Fig $: 2 b$ indicates the origin of profunda: Common trunk for profunda brachii and superior ulnar collateral branch of brachial artery in 2 cases (6.67\%). Fig: 3a shows the dilated tortuous brachial artery and it terminated at the level of neck of radius. Fig:3b indicates the positioning of median nerve posterior to the 
Jessy Rose George, et al., Thomas Francis. MORPHOLOGY AND VARIATIONS OF BRACHIAL ARTERY IN CADAVERS.

brachial artery in the entire arm. Fig :4 indicates the division of brachial artery seen in the lower $3^{\text {rd }}$ of arm, with median nerve passing between the two division.

Fig. 1a:Accessory Brachial artery. 2 \& 3 Divisions of Brachial artery, 4. Median Nerve passing between the divisions.

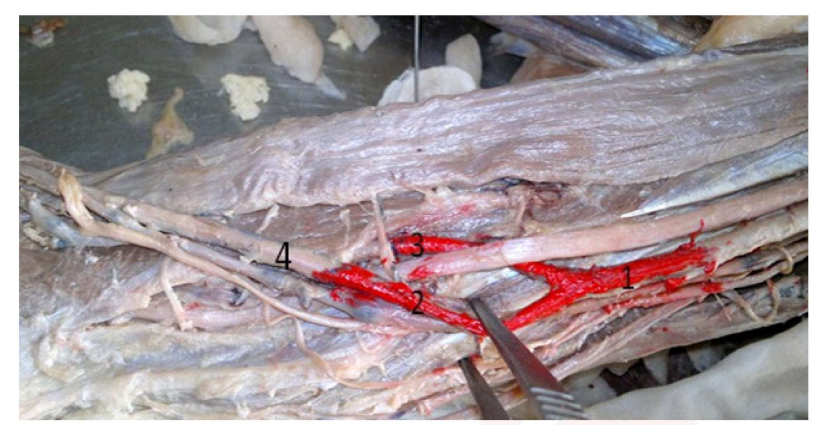

Fig. 1b:Median Nerve passing between superficial and deep brachial artery.

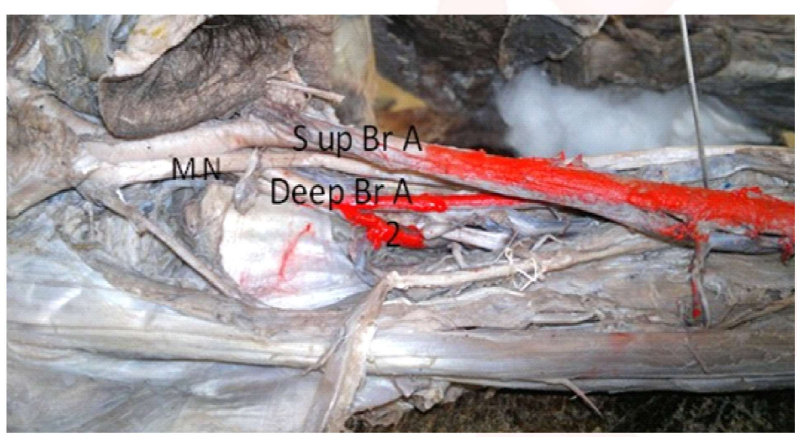

Fig. 2a:Trifurcating pattern of brachial artery into 1 . Brachial Artery 2. Ulnar Artery 3. Common interosseous artery, 4. Radial artery.

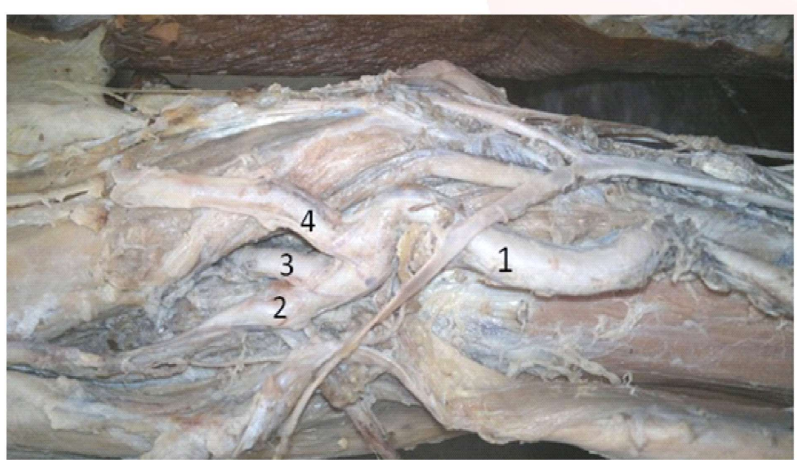

Fig. 2b:Origin of profunda common trunk for profunda brachii and superior ular collateral branch of brachial artery. 1. Common trunk, 2. Superior Ulnar collateral 3. Profunda brachii.

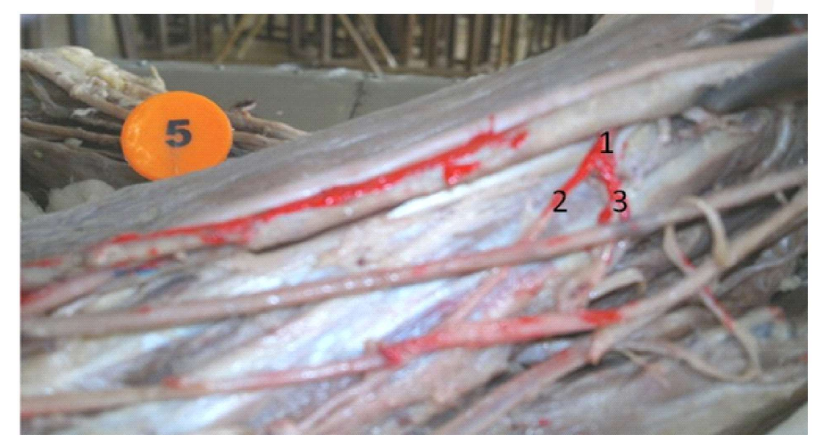

Fig. 3a:Course of Median Nerve placed behind the dilated tortuous Brachial artery.

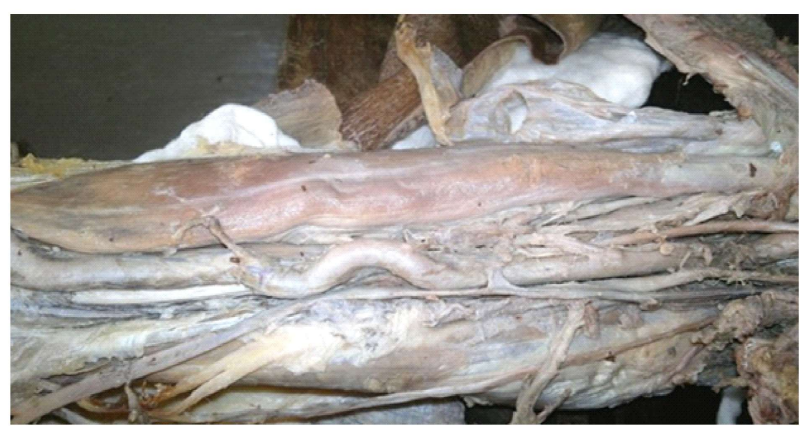

Fig. 3b: Course of Median Nerve place behind the Brachial artery.

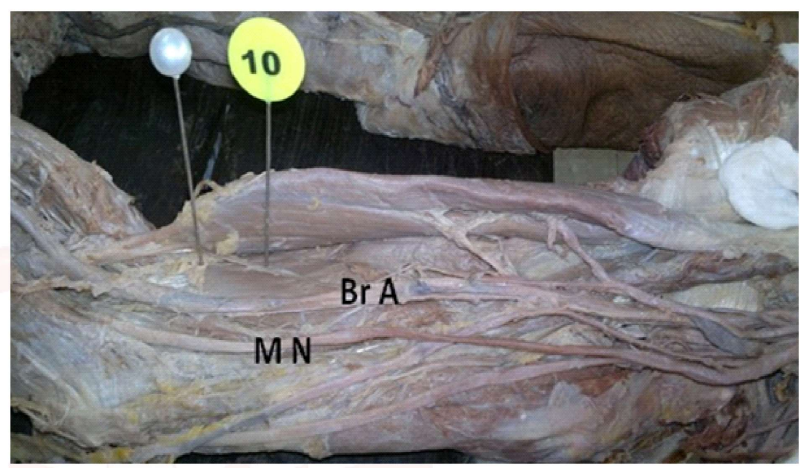

Fig. 4: High origin of Brachioradial at distal $3^{\text {rd }}$ of arm. Median nerve passing between two division. 1. Ulnar Artery 2. Anterior Interosseous artery 3. Posterior interosseous.

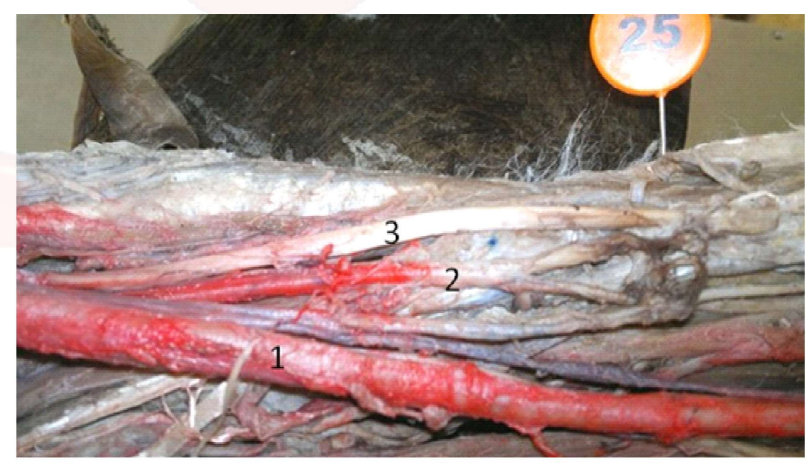

\section{DISCUSSION}

Variations in the pattern of upper limb arteries have been reported since the 17 th century. Quain's in 1844 published the first systematic description and classification of these variations on the basis of cadaver dissection and angiographic studies[7]. Three variations in upper limb arteries are fairly common. The most commonly reported variation in the higher division of Brachial Artery into Radial Artery and Ulnar Artery above the Cubital fossa.According to the compendium of human anatomic variation, major variations are present in about $25 \%$ of the subjects studied for the Brachial Artery. The variations in the form of high proximal 
division into terminal branches occur in the Radial Artery (15\%), Ulnar Artery (2\%), and common interosseous artery.Various authors have mentioned about the incidence of high origin of Radial Artery. This HD may occur at any point in the branches of the brachial artery:These areArteria profunda brachii, Nutrient artery of the humerus, Superior ulnar collateral artery and Inferior ulnar collateral (supratrochlear artery).

According to Adachi (1928), this superficial brachial artery is so called because it runs superficial to median nerve, whereas usually the brachial artery runs deep to median nerve[8].The superficial brachial artery arises from axillary artery or from proximal $1 / 3^{\text {rd }}$ of brachial artery usually between contributions of medial and lateral cords of brachial plexus to median nerve. It is superficial to muscles of the arm under brachial fascia lying slightly more lateral than brachial artery and, in the elbow, region divides into radial and ulnar arteries[9].

The superficial brachial artery may replace the main trunk or may be accompanied by equally important, less important or more important trunk running parallel and deep to median nerve in normal position. In these cases, superficially placed vessels may continue as radial or more rarely ulnar artery.

Keen (1961) subdivided superficial brachial artery found in $12.3 \%$ dissections into 3 types[10]. Namely, (a) Those superficial brachial arteries which continue in cubital fossa and bifurcate as usual into radial and ulnar arteries (3.6\%).(b) Superficial brachial artery continues as radial artery and known as 'High origin of radial artery' (5.9\%)and (c) Superficial brachial artery continues as ulnar artery and known as 'High origin of ulnar artery'(2.8\%).In the present study, we have reported $6.67 \%$ cases as type-B.No cases of type a and type-C could be found in the specimens studied.

McCormack et al (1953) encountered a rare entity ie, Accessory brachial artery[11].

In the present study in one case $(3.33 \%)$ which arose from middle $3^{\text {rd }}$ of arm Throughout its course it lay lateral tomain brachial artery; however, at lower $3^{\text {rd }}$ of the arm it passed deep to median nerve and $8 \mathrm{~cm}$ proximal to its termination crossed back over median nerve. It rejoined brachial artery in antecubital fossa $23 \mathrm{cms}$ beyond its origin.

High origin of radial and ulnar artery forms the highest percentage of variations of brachial artery. A high origin radial artery occurring in $14.27 \%$ individuals, may arise as high as the axillary artery but most commonly it arises from the proximal one third of the arm $[12,13]$. In the arm, it lies anterior to median nerve and in the forearm, it takes normal course [14].6.67\% cases of Superficial brachioradial A foundin the present study.

Karlsson and Niechajev (1982) in angiographic observations, found high origin of radial artery in $10 \%$ patients, the parent trunk being axillary artery in $12.5 \%$, proximal $1 / 3$ of brachial in $62.5 \%$ and middle $1 / \beta$ of brachial in $25 \%[15]$. They could find high origin of ulnar artery in $1 \%$ cases only. In the forearm it courses across the forearm flexors to medial side of the arm. They found it in $2.26 \%$ cases [ 16 ], $2.1 \%$ by Gruber (1848), $2 \%$ of cases [17], $1.7 \%$ cases[7], $0.8 \%$ cases [12]. Brachial artery in its upper part may also give rise to subscapular and posterior circumflex humeral, normally branches of the axillary; in its lower part to the radial recurrent and at its bifurcation to the interosseous artery or to median artery.

\section{CONCLUSION}

Knowledge of possible variations in the branching pattern of various arteries is important during vascular and reconstructive surgery.These variations are of great importance in cardiac catheterization for angioplasty and arterial grafting also. These variations may cause difficulties while measuring the blood pressure. Being superficial, the radial artery may be mistaken as a vein and the accidental radial cannulation with drugs may cause reflex vascular occlusion, resulting in disastrous gangrene of hand like arterial thrombosis, producing ischemia may be related to high risk of tissue gangrene or amputation.Angiographic images and Doppler ultrasound imaging are of considerable importance during invasive and noninvasive investigative procedures due to this kind of variations. The surgeons should be aware of arterial variations in the region before embarking on the procedure. 


\section{Conflicts of Interests: None}

\section{REFERENCES}

[1]. AnagnostoPoulou S, Venieratos D. An unusual branching pattern of the superficial brachial artery accompanied by an ulnar nerve with two roots. J Anat, 1999; 195: 471-476.

[2]. Benjamin Le, Heo I, Keshet E. A plasticity window for blood vessel remodeling is defined by pericyte coverage of the preformed endothelial network and isregulated by PDGF-B and VEGF. Development, Anat Res, 1998; 231: 136-144.

[3]. Nakatani T, Izumi A, Tanaka S. Bilateral superficial median arteries. J Anat, 1999; 194: 475-477.

[4]. Sañudo Jr, Mirapeix Rm, García R, Rodríguez N. A superficial ulnar artery anastomosing with a larger anterior interosseous artery to supply the wrist and hand. J Anat, 1998;192: 439-441.

[5]. Diz JC, Ares X, Tarrazo AM, Alvarez J, Meaños ER. Bilateral superficial radial artery at the wrist. Acta AnaesthesiolScand, 1998; 42: 1020.

[6]. Rodríguez N, Burton GJ, Deu J, Sañudo JR. Development of the arterial pattern in the upper limb of staged human embryos: normal development and anatomic variations. J Anat, 2001; 199: 407-417.

[7]. Quain R. Anatomy of the Arteries of the Human Body. Taylor \& Walton, London, 1844; pp 326-337.

[8]. Adachi B. The superficial ulnar artery: development and surgical significance. Clin Anat,1928; 9: 128132.
[9]. Anson, Aizawa Y, Isogai S, Izumiyama M, Horiguchi M. Morphogenesis of the primary arterial trunks of the forelimb in the rat embryos. AnatEmbryol, 1999; 20: 573-584.

[10]. Keen JA. A study of the arterial variations in the limbs with special reference to symmetry of vascular patterns. Am J Anat, 1961; 108: 245-261.

[11]. Mc Cormack LJ, Cauldwell EW, Anson J. Brachial and antebrachial arterial patterns. Surg GynecolObstetr, 1953; 96: 43-54.

[12]. De Garis, Swartley, Deligonul U, Gabliani G, Kern MJ, Vandormel M. Percutaneous brachial catheterization: the hidden hazard of high brachial artery bifurcation Catheter Cardiovasc Diag,1988; 14: 4445.

[13]. Miller Y, Brown MJ, Edstrom LE, Zienowicz RJ. A symptomatic radial artery anomaly and its surgical treatment.J Hand Surg. 1999; 24: 178-181.

[14]. Huber I, Heden P, Gylbert L. Anomaly of the radial artery encountered during elevation of the radial forearm flap. J Reconstr Microsurg,1990; 6: 139141.

[15]. Carlson BM, Cohen SM. Accidental intra-arterial injection of drugs. The Lancet, 1999; 255: 409-417.

[16]. Coulouma, Larsen WJ. Arterial Variations in Man. JF Bergmann Verlag, München,1993; pp 71-73.

[17].Muller E. Beiträgezur. Morphologie des Gefäss systems. I. Die Armarterien des Menschen. AnatHefte, 1903; 22:377-575.

How to cite this article:
Jessy Rose George, Joseph Francis, Jeffy Elizabeth Samuel,
Thomas Francis. MORPHOLOGY AND VARIATIONS OF BRACHIAL
ARTERY IN CADAVERS. Int J Anat Res 2019;7(2.3):6680-6684. DOI:
10.16965/ijar.2019.202 